\title{
Predictive Factors of Response to Proton Pump Inhibitors in Korean Patients With Gastroesophageal Reflux Disease
}

\author{
Sung Eun Kim, ${ }^{1,2}$ Nayoung Kim, ${ }^{1,3 *}$ Sooyeon $\mathrm{Oh}^{3}{ }^{3}$ Hee Man Kim, ${ }^{4}$ Moo In Park, ${ }^{2}$ Dong Ho Lee, ${ }^{1,3}$, and Hyun Chae Jung ${ }^{3}$ \\ ${ }^{1}$ Department of Internal Medicine, Seoul National University Bundang Hospital, Seongnam, Gyeonggi-do, Korea; ${ }^{2}$ Department of Internal \\ Medicine, Kosin University College of Medicine, Busan, Korea; ${ }^{3}$ Department of Internal Medicine and Liver Research Institute, Seoul National \\ University College of Medicine, Seoul, Korea; and ${ }^{4}$ Department of Internal Medicine, Yonsei University Wonju College of Medicine, Wonju, \\ Gangwon-do, Korea
}

\section{Background/Aims}

Proton pump inhibitors (PPIs) are widely used in the treatment of gastroesophageal reflux disease (GERD). However, some patients fail to respond to PPI therapy. We investigated the efficacy of response to PPI therapy in patients with GERD symptoms.

\section{Methods}

A total of 179 subjects with GERD symptoms were prospectively enrolled and diagnosed with non-erosive reflux disease (NERD, $n=100)$ and erosive reflux disease $(n=79)$ by gastroscopy and Bernstein test and/or 24-hour esophageal pH testing. Subjects then received a standard dose of daily PPI therapy for at least 4 weeks. PPI therapy response was evaluated using questionnaires including questions about demographics, GERD symptoms, GERD impact scale, Epworth sleepiness scale, Pittsburgh sleep quality index (PSQI), hospital anxiety and depression scale, and abbreviated version of the World Health Organization quality of life scale.

Results

The rates of complete $(\geq 80 \%)$, satisfactory $(\geq 50 \%)$, partial $(<50 \%)$, and refractory response in the 179 participants were $41.3 \%, 30.2 \%, 18.4 \%$, and $10.1 \%$, respectively. Thus, overall response rate (complete and satisfactory responses) was $71.5 \%$. Multivariate analysis showed body mass index $<23 \mathrm{~kg} / \mathrm{m}^{2}(\mathrm{OR}, 2.20 ; 95 \% \mathrm{Cl}, 1.12-4.34)$, higher total PSQI score (OR, 1.20; $95 \% \mathrm{Cl}, 1.05-1.35)$, history of psychotherapy or neuropsychiatric medication (OR, 2.44; $95 \% \mathrm{Cl}, 1.23-4.85)$, and NERD (OR, $3.30 ; 95 \% \mathrm{Cl}, 1.54-7.11)$ were associated with poor response to PPI therapy.

\section{Conclusions}

Psychological factors, sleep dysfunction, body mass index $<23 \mathrm{~kg} / \mathrm{m}^{2}$, and NERD seem to be the major factors that lead to a poor response to PPI treatment in patients with GERD symptoms.

(J Neurogastroenterol Motil 2015;21:69-77)

Key Words

Esophagitis; Gastroesophageal reflux; Proton pump inhibitors; Psychology; Sleep disorders

Received: July 3, 2014 Revised: November 6, 2014 Accepted: November 9, 2014

(c) This is an Open Access article distributed under the terms of the Creative Commons Attribution Non-Commercial License (http://creativecommons. org/licenses/by-nc/3.0) which permits unrestricted non-commercial use, distribution, and reproduction in any medium, provided the original work is properly cited.

*Correspondence: Nayoung Kim, MD, PhD

Department of Internal Medicine, Seoul National University Bundang Hospital, 173-82, Gumi-ro, Bundang-gu, Seongnam, Gyeonggi-do 463-707, Korea

Tel: +82-31-787-7008, Fax: +82-31-787-4051, E-mail: nayoungkim49@empas.com

Financial support: This research was supported from the Seoul National University Bundang Hospital Research fund (Grant No. 06-2013-082). Conflicts of interest: None.

Author contributions: Sung Eun Kim interpreted and analyzed the data, and wrote the present study; Nayoung Kim designed, organized and mediated the present study, and supervised the manuscript; Sooyeon Oh has organized the data for statistical analysis; Hee Man Kim and Moo In Park helped the interpretation of the data which was used in the current study; Dong Ho Lee performed critical revision of the data for the important intellectual content; and Hyun Chae Jung did critical revision of the manuscript for important content. ORCID: Nayoung Kim, http://orcid.org/0000-0002-9397-0406. 


\section{Introduction}

Gastroesophageal reflux disease (GERD) is one of the most prevalent gastrointestinal disease, and is defined as a condition that develops when the reflux of stomach contents causes troublesome symptoms and/or complications. ${ }^{1,2}$ GERD is generally categorized into erosive reflux disease (ERD) and non-erosive reflux disease (NERD) using gastroscopy and/or 24-hour esophageal $\mathrm{pH}$ monitoring. Physicians generally recommend lifestyle modifications (eg, weight loss, elevating the head of the bed, and avoiding late-night meals) and medications (eg, proton pump inhibitor $[\mathrm{PPI}]$, histamine-2 receptor antagonist $\left[\mathrm{H}_{2} \mathrm{RA}\right]$, and antacid) for management of GERD. ${ }^{3}$ PPIs are the most effective drugs for treating patients with GERD symptoms, and therefore, GERD patients are commonly treated with PPIs for extended periods of time. However, several adverse effects of long-term PPI use have been reported, including community-acquired pneumonia, Clostridium difficile-associated disease, hip fractures, and hypomagnesemia. ${ }^{4}$ In some observational community-based studies, troublesome dominant symptoms such as heartburn or regurgitation did not subside in spite of treatment with PPI. ${ }^{5-7}$

Several recent studies suggest that female gender, lower body mass index (BMI), anxiety, and depressive disorders are associated with poor response to PPI treatment in patients with GERD. ${ }^{8,9}$ However, response rates and related factors after PPI therapy are significantly different by country. Thus, well-designed studies for assessing the efficacy of PPI therapy in patients with GERD symptoms are needed. The ability to identify PPI responders and non-responders prior to PPI therapy will improve the treatment approach for patients with GERD symptoms and may reduce adverse effects. ${ }^{9}$

The present study aimed to prospectively investigate the efficacy of PPI therapy in patients with ERD and NERD, and to evaluate the predictors of response to PPI treatment in patients with GERD symptoms.

\section{Materials and Methods}

\section{Patients}

Patients with GERD experiencing typical (such as heartburn and acid regurgitation) and/or atypical (such as hoarseness, chest pain, and epigastric soreness) symptoms at least once per month were prospectively enrolled at the Seoul National University
Bundang Hospital (SNUBH) from July 2008 to December 2012. All participants underwent gastroscopy and completed a questionnaire that included the GERD impact scale (GIS) for GERD symptoms. Participants were encouraged to undergo an acid perfusion study (Bernstein test) during esophageal manometry or 24-hour esophageal $\mathrm{pH}$ monitoring in order to diagnose NERD vs ERD. Among the GERD symptoms patients, the patients who were verified with erosive esophagitis (Los Angeles grades as A to D) by gastroscopy were classified as ERD. The patients with GERD symptoms who had a positive ambulatory 24-hour esophageal pH monitoring or Bernstein test during esophageal manometry, with a normal finding at the gastroesophageal junction as confirmed by gastroscopy were classified as NERD. Symptoms of NERD were checked in terms of frequency and symptom characteristics.

Esophageal manometry was performed in all of the enrolled patients. BMI, smoking and alcohol habits, comorbidities, and history of psychotherapy or neuropsychiatric medication were collected via patient interview as well as from electronic medical records. Any patient who had visited a psychiatrist or taken neuropsychiatric medication at least once was considered to have a history of psychotherapy or neuropsychiatric medication. Sleep dysfunction, anxiety, depression, and quality of life (QOL) were evaluated by questionnaire under the supervision of a well-trained interviewer. Patients who underwent a gastrointestinal operation, esophageal motility disorder, Barrett's esophagus, functional heartburn (FH), peptic ulcers, malignancy in the gastrointestinal tract, or systemic disease requiring chronic medication (except for hypertension and diabetes mellitus) were excluded from this study. Subjects who had taken a PPI or an $\mathrm{H}_{2} \mathrm{RA}$ within 4 weeks of the study were also excluded. $\mathrm{FH}$ was diagnosed if ambulatory 24-hour esophageal $\mathrm{pH}$ monitoring and the Bernstein test were negative and findings at the gastroesophageal junction were normal on gastroscopy.

The institutional review board of SNUBH reviewed and approved the current study protocol, and we had the informed consent from all participants. The ClinicalTrials.gov registration number is NCT01797939. All authors of the current study had access to the study data and reviewed and approved the final manuscript.

\section{Gastroscopy}

Gastroscopy (GIF H260; Olympus, Tokyo, Japan) was carried out to identify the status of gastroesophageal junction including erosive esophagitis, Barrett's esophagus, and hiatal hernia. 
Barrett's esophagus is defined as an endoscopically salmon like projection from the $\mathrm{Z}$-line and the replacement of the normal stratified squamous epithelium by columnar epithelium with specialized intestinal metaplasia containing goblet cells in a biopsy of the distal esophagus. ${ }^{10}$ And, the hiatal hernia was endoscopically identified when the distance from the esophagogastric junction to the diaphragmatic impingement was more than $1 \mathrm{~cm}^{11}$ One expert endoscopist (N.K.) performed and investigated every endoscopic evaluation.

\section{Ambulatory 24-hour Esophageal pH Monitoring}

Twenty-four hour esophageal $\mathrm{pH}$ monitoring was performed with a single channel antimony $\mathrm{pH}$ probe (Synetics Medical, Queluz, Portugal) positioned $5 \mathrm{~cm}$ above the upper margin of the lower esophageal sphincter (LES). ${ }^{2}$ Intraesophageal $\mathrm{pH}$ monitoring was recorded by using an Orion $\mathrm{pH}$ recorder which was connected to the Makes Measurement Simple database (version 8.1; MMS, Enschede, the Netherlands) during 24 hours. Each patient recorded meal times, postural changes, and the timing of any symptoms that occurred during the 24-hour study period. Acid exposure over $4.2 \%$ of the total time $(\mathrm{pH}<4)$ or a positive symptom index $(>50 \%)$ was considered positive results.

\section{Acid Perfusion Test}

The Bernstein test was conducted during esophageal manometry. A polyethylene catheter (outer diameter $4.5 \mathrm{~mm}$, inner diameter $0.8 \mathrm{~mm}$; Mui Scientific, Mississauga, Ontario, Canada) was positioned $5 \mathrm{~cm}$ above the upper margin of the LES. ${ }^{2}$ And, $0.1 \mathrm{~N}$ hydrochloric acid was infused via the catheter at 6-7 $\mathrm{mL} / \mathrm{min}$ without any information to participants, followed by $0.9 \%$ normal saline normal saline more than 10 -minute period. Test results were considered positive if the participants complained of chest pain or discomfort as like as GERD symptoms while the acid solution was being infused, and if the symptoms were relieved when the acid solution was replaced by $0.9 \%$ normal saline solution. This procedure was performed twice to confirm that the test results were reproducible.

\section{Conventional Manometry}

We used a conventional manometry which had 8 channels water perfused manometry catheter (UPS-2020; Medical Measurements Systems, Enschede, The Netherlands) and sleeve sensor included at the distal end. It was positioned to the esophagus through the nose. A pull-through technique was conducted to de- cide the LES pressure. Patients were performed the 10 swallows comprising 5-mL water at 20-second intervals in order to estimate the basal and residual LES pressure, amplitude and duration of esophageal body contraction. ${ }^{12}$

\section{High-resolution Manometry}

We used a high-resolution manometry (HRM) with 32 pressure sensors spaced at $1-\mathrm{cm}$ intervals (InSIGHT HRiM system; Sandhill Scientific, Highlands Ranch, CO, USA). All patients fasted at least 6 hours prior to HRM, and HRM was positioned from the hypopharynx to the stomach through the nasal passage with the patients in the sitting position. The manometric protocol is composed of a 5-minute period to evaluate basal sphincter pressure with ten $5 \mathrm{~mL}$ of water swallows. Manometric data were analyzed by using the BioVIEW software (Sandhill Scientific), and pressure readings were changed into topographic (color contour) plots to provide an uninterrupted image of the pressure throughout the segment considered. ${ }^{12,13}$

\section{Questionnaires}

Two questionnaires, such as, 5 GERD symptoms questionnaire and GIS, were used. First, 5 GERD symptoms were identified: heartburn, acid regurgitation, chest pain, hoarseness, and epigastric soreness. ${ }^{2,14,15}$ The GIS consisted of 5 questions about the aforementioned symptoms, and 4 questions about QOL, including sleep patterns, eating and drinking habits, job or daily activities, and additional medication. ${ }^{14,15}$ A modified 5-point Likert scale was used to assess the frequency of symptoms ( 5 , never; 4 , 1-2 times per month; 3, 1-2 times per week; 2, 3-4 times per week; 1, daily). ${ }^{16}$ Thankfully, AstraZeneca LP (C)2001) allowed the use of text from the GIS.

The Epworth sleepiness scale (ESS) ${ }^{17}$ and Pittsburgh sleep quality index (PSQI) ${ }^{15,18}$ were utilized to identify sleep dysfunction. The ESS is composed of 8 self-rated items, each scored from 0-3, which measure participant's habitual "likelihood of dozing or falling asleep" during normal daily activities. The ESS score represents the sum of individual items, and ranges from $0-24$. Scores $>10$ indicate significant sleepiness. ${ }^{18,19}$ The PSQI is a 19-item self-rated questionnaire, which consists of 7 component scores, including subjective sleep quality, sleep latency, sleep duration, habitual sleep efficiency, sleep disturbances, use of sleeping medication, and daytime dysfunction. Each component is rated from 0 to 3 , and the 7 component scores are added to acquire a global score ranging from 0 to 21 , with higher scores indicating poor sleep quality. ${ }^{18,19}$ 
The hospital anxiety and depression scale (HADS) was developed to identify possible and probable anxiety disorders and depression among non-psychiatric subjects. HADS is classified as an anxiety subscale and a depression subscale, and both subscales consisted of seven items. The scores range of each item is $0-3$, and a higher HADS score indicates that the participant is more anxious or depressive. In addition, a score of each subscale more than 7 represents that the probability of anxiety disorder or depression is high. ${ }^{18,20}$

The participants QOL was evaluated by the World Health Organization quality of life scale abbreviated version (WHOQOLBREF). The WHOQOL-BREF assesses overall QOL and general health by evaluating physical health, psychological health, social relationships, and environmental conditions. Each item is scored using a 5-point Likert scale. The scores are then expressed on a linear scale (range 0-100), with higher scores indicating better QOL. ${ }^{18,21}$

All questionnaires used in this study, such as, 5 GERD symptoms questionnaire, GIS, ESS, PSQI, WHOQOL-BREF, and HADS, were translated into Korean. ${ }^{22-24}$

\section{Proton Pump Inhibitor Treatment and Symptom Assessment}

Participants with GERD symptoms were treated with a standard dose of PPIs (eg, esomeprazole, rabeprazole, pantoprazole, omeprazole, and lansoprazole), and symptoms were re-assessed after four weeks of treatment. Participants who completed $\geq 80 \%$ of PPI therapy were considered compliant, and those who completed $<80 \%$ of PPI therapy were considered non-compliant. Participants were excluded if they were non-compliant or lost to follow-up. Patients were asked to describe changes in symptoms using percentages, and GERD symptoms before and after PPI were compared. Response to PPI treatment was classified as either a complete response (more than $80 \%$ of symptom resolution), satisfactory response (symptoms remained less than 50\%), partial response (symptoms remained for more than 50\%), or refractory response (unresponsive to PPI therapy). ${ }^{2}$ Patients with a complete or satisfactory response were considered responders, and patients with a partial or refractory response were considered non-responders. ${ }^{2}$

\section{Statistical Methods}

All statistical analyses were performed using the statistical package for the social sciences software version 18.0 (SPSS, Chicago, IL, USA). Continuous variables were compared using Student's $t$ test, and categorical variables were compared using the Chi-squared $\left(\chi^{2}\right)$ test. A logistic regression analysis was used to determine predictive factors for improvement of GERD symptoms after PPI therapy, which were expressed as an OR and $95 \%$ CI. $P$-values $<0.05$ were considered statistically significant.

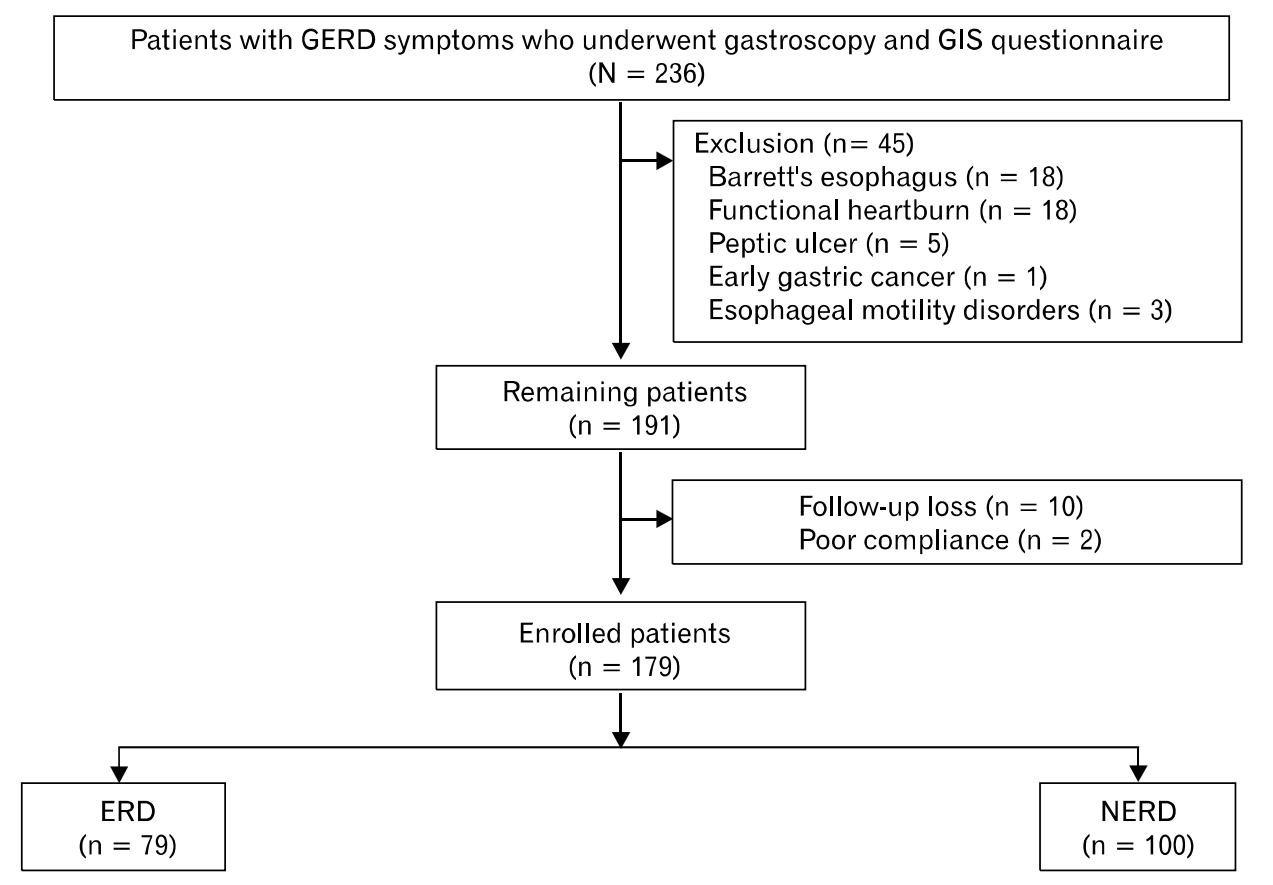

Figure. Flow chart of study participants. GERD, gastroesophageal reflux disease; GIS, GERD impact scale; ERD, erosive reflux disease; NERD, non-erosive reflux disease. 


\section{Results}

\section{Proton Pump Inhibitor Response Rates}

A total of 236 patients with GERD symptoms filled out the GIS questionnaire. Of these patients, 45 were excluded due to diagnosis of diseases including Barrett's esophagus $(\mathrm{n}=18), \mathrm{FH}$ $(\mathrm{n}=18)$, peptic ulcer $(\mathrm{n}=5)$, early gastric cancer $(\mathrm{n}=1)$, and esophageal motility disorders $(n=3,2$ patients with achalasia and 1 with diffuse esophageal spasm). In addition, 10 participants were lost to follow-up and 2 were excluded due to non-compliance. Ultimately, 179 patients were enrolled in the study, 100 of whom were diagnosed with NERD and 79 of whom were diagnosed with ERD (Figure).

Response rates to PPI were significantly different between the ERD and NERD groups. The ERD group had a complete response rate of $55.7 \%$, while the NERD group had a $30.0 \%$ complete response rate. The satisfactory response rate was $29.1 \%$ for ERD and $31.0 \%$ for NERD, while the partial response rate was $12.7 \%$ for ERD and $23.0 \%$ for NERD. Finally, the refractory response rate was $2.5 \%$ for ERD and $16.0 \%$ for NERD $(P=0.001)$ (Table 1). Thus, the overall proportion of PPI responders in the ERD and NERD groups were $84.8 \%$ and $61.0 \%$, respectively $(P<0.001)$. The complete, satisfactory, partial, and refractory responses in the ERD and NERD groups combined were $41.3 \%, 30.2 \%, 18.4 \%$, and $10.1 \%$, respectively. The overall proportions of PPI responders and PPI non-responders in patients with GERD symptoms (both ERD and NERD) were $71.5 \%$ and $28.5 \%$, respectively (Table 1 ).

Table 1. Symptom Responses after Proton Pump Inhibitor Therapy According to the Subtype of Gastroesophageal Reflux Disease

\begin{tabular}{|c|c|c|c|c|}
\hline & $\operatorname{NERD}(\mathrm{n}=100)$ & $\operatorname{ERD}(\mathrm{n}=79)$ & $P$-value & Overall response rate \\
\hline PPI response (n [\%]) & & & $<0.001$ & \\
\hline Responders & $61(61.0)$ & $67(84.8)$ & & $128(71.5)$ \\
\hline Complete & $30(30.0)$ & $44(55.7)$ & & $74(41.3)$ \\
\hline Satisfactory & $31(31.0)$ & $23(29.1)$ & & $54(30.2)$ \\
\hline Non-responders & $39(39.0)$ & $12(15.2)$ & & $51(28.5)$ \\
\hline Partial & $23(23.0)$ & $10(12.7)$ & & $33(18.4)$ \\
\hline Refractory & $16(16.0)$ & $2(2.5)$ & & $18(10.1)$ \\
\hline
\end{tabular}

NERD, non-erosive reflux disease; ERD, erosive reflux disease; PPI, proton pump inhibitor.

Table 2. Baseline Characteristics According to Proton Pump Inhibitor Responses

\begin{tabular}{|c|c|c|c|}
\hline & $\begin{array}{l}\text { PPI responders } \\
\quad(\mathrm{n}=128)\end{array}$ & $\begin{array}{l}\text { PPI non-responders } \\
\qquad(\mathrm{n}=51)\end{array}$ & $P$-value \\
\hline Age $($ mean $\pm \mathrm{SD}, \mathrm{yr})$ & $55.0 \pm 13.1$ & $55.7 \pm 12.7$ & 0.746 \\
\hline Gender (n [\%]) & & & 0.091 \\
\hline Male & $82(64.1)$ & $25(49.0)$ & \\
\hline Female & $46(35.9)$ & $26(51.0)$ & \\
\hline $\mathrm{BMI}(\mathrm{n}[\%])$ & & & 0.024 \\
\hline$<23 \mathrm{~kg} / \mathrm{m}^{2}$ & $38(29.7)$ & $25(49.0)$ & \\
\hline$\geq 23 \mathrm{~kg} / \mathrm{m}^{2}$ & $90(70.3)$ & $26(51.0)$ & \\
\hline Cigarette smoking (n $[\%]$ ) & $33(25.8)$ & $7(13.7)$ & 0.111 \\
\hline Alcohol intake (n [\%]) & $55(43.0)$ & $21(41.2)$ & 0.868 \\
\hline \multicolumn{4}{|l|}{ Comorbidity (n [\%]) } \\
\hline Hypertension & $29(22.7)$ & $8(15.7)$ & 0.413 \\
\hline Diabetes mellitus & $16(12.5)$ & $2(3.9)$ & 0.103 \\
\hline NP follow-up or NP medication & $36(28.1)$ & $26(51.0)$ & 0.005 \\
\hline Hiatal hernia (n [\%]) & $19(14.8)$ & $6(11.8)$ & 0.811 \\
\hline
\end{tabular}

PPI, proton pump inhibitor; SD, standard deviation; BMI, body mass index; NP, neuropsychiatry. 


\section{Comparison of Questionnaires Contents According to Proton Pump Inhibitor Responses and Predictive Factors for Symptom Improvement After Proton Pump Inhibitor Therapy}

When participants were grouped according to PPI response, there were significantly more PPI non-responders with a BMI < $23 \mathrm{~kg} / \mathrm{m}^{2}$ than PPI-responders (49.0\% vs $29.7 \%$ ). A history of psychotherapy or neuropsychiatric medication was also significantly more common in PPI non-responders $(51.0 \%)$ than PPI responders $(28.1 \%)(P=0.024$ and $P=0.005$, respectively) (Table 2).

Of the 5 GERD symptoms considered in this study (heartburn, acid regurgitation, chest pain, hoarseness and epigastric soreness), frequency of chest pain was significantly higher in PPI non-responders (68.9\%) compared to PPI responders (49.2\%) $(P=0.020)$. The remaining symptoms (heartburn, acid regurgitation, hoarseness, and epigastric soreness) were not signifi- cantly different between the 2 groups (Table 3 ). In addition, the total GIS, ESS, HADS, and WHOQOL-BREF scores were not significantly different between the 2 groups. However, the total PSQI score was significantly higher in PPI non-responders $(6.8 \pm 3.3)$ than PPI responders $(5.4 \pm 2.4)(P=0.007)($ Table 3$)$.

Multivariate analyses demonstrated that NERD (OR, 3.30; 95\% CI, 1.54-7.11), BMI < $23 \mathrm{~kg} / \mathrm{m}^{2}$ (OR, 2.20; 95\% CI, 1.12-4.34), history of psychotherapy or neuropsychiatric medication (OR, 2.44; 95\% CI, 1.23-4.85), and higher total PSQI score $(\mathrm{OR}, 1.20 ; 95 \% \mathrm{CI}, 1.05-1.35)$ were associated with a non-response to PPI therapy (Table 4). When ERD and NERD patients were evaluated separately, BMI $<23 \mathrm{~kg} / \mathrm{m}^{2}$ (OR, 2.74; 95\% CI, 1.20-6.30) and higher total PSQI score (OR, 1.18; $95 \%$ CI, 1.02-1.37) in NERD patients were associated with a non-response to PPI therapy (Table 5).

\section{Discussion}

Although the present study was a small-scale prospective

Table 3. Comparison of Reflux Symptoms, Sleep Dysfunction, Anxiety, Depression, and Quality of Life in the Study Subjects

\begin{tabular}{|c|c|c|c|}
\hline & $\begin{array}{l}\text { PPI responders } \\
\quad(\mathrm{n}=128)\end{array}$ & $\begin{array}{l}\text { PPI non-responders } \\
\qquad(\mathrm{n}=51)\end{array}$ & $P$-value \\
\hline \multicolumn{4}{|l|}{ GERD symptoms (n [\%]) } \\
\hline Heartburn & $82(64.1)$ & $38(74.5)$ & 0.219 \\
\hline Acid regurgitation & $89(69.5)$ & $33(64.7)$ & 0.595 \\
\hline Chest pain & $63(49.2)$ & $35(68.9)$ & 0.020 \\
\hline Hoarseness & $62(48.4)$ & $29(56.9)$ & 0.325 \\
\hline Epigastric soreness & $73(57.0)$ & $33(64.7)$ & 0.401 \\
\hline \multicolumn{4}{|l|}{ GIS score $($ mean $\pm \mathrm{SD})$} \\
\hline Total & $36.0 \pm 6.8$ & $34.3 \pm 6.9$ & 0.120 \\
\hline GERD symptoms & $18.4 \pm 4.7$ & $17.3 \pm 4.6$ & 0.182 \\
\hline Impact of symptoms & $17.8 \pm 2.9$ & $16.9 \pm 3.4$ & 0.136 \\
\hline Total ESS score (mean $\pm \mathrm{SD})$ & $12.0 \pm 3.4$ & $12.3 \pm 3.3$ & 0.513 \\
\hline Total PSQI score (mean $\pm \mathrm{SD})$ & $5.4 \pm 2.4$ & $6.8 \pm 3.3$ & 0.007 \\
\hline \multicolumn{4}{|l|}{ HADS score $($ mean $\pm \mathrm{SD})$} \\
\hline Total & $13.0 \pm 5.7$ & $14.3 \pm 5.6$ & 0.197 \\
\hline Anxiety & $6.0 \pm 3.0$ & $6.6 \pm 3.0$ & 0.204 \\
\hline Depression & $7.1 \pm 3.0$ & $7.7 \pm 3.0$ & 0.253 \\
\hline \multicolumn{4}{|c|}{ WHOQOL-BREF score (mean $\pm \mathrm{SD})$} \\
\hline Total & $77.2 \pm 9.0$ & $75.8 \pm 8.6$ & 0.344 \\
\hline Overall & $6.0 \pm 1.1$ & $5.7 \pm 1.1$ & 0.111 \\
\hline Physical Health & $19.3 \pm 2.4$ & $19.3 \pm 2.5$ & 0.931 \\
\hline Psychological & $17.0 \pm 2.6$ & $16.6 \pm 2.5$ & 0.367 \\
\hline Social Relationships & $9.8 \pm 1.4$ & $9.9 \pm 1.2$ & 0.537 \\
\hline Environment & $25.1 \pm 3.7$ & $24.3 \pm 3.6$ & 0.191 \\
\hline
\end{tabular}

PPI, proton pump inhibitor; GERD, gastroesophageal reflux disease; GIS, GERD impact scale; SD, standard deviation; ESS, Epworth sleepiness scale; PSQI, Pittsburgh sleep quality index; HADS, hospital anxiety and depression scale; WHOQOL-BREF, World Health Organization quality of life scale abbreviated version. 
Table 4. Factors Predicting Poor Response to Proton Pump Inhibitor Therapy in Patients With Gastroesophageal Reflux Disease Symptoms

\begin{tabular}{lccc}
\hline \multirow{2}{*}{ Variables } & \multicolumn{2}{c}{ Poor response to PPI } & \\
\cline { 2 - 3 } & OR & $95 \%$ CI & \\
\hline BMI $<23 \mathrm{~kg} / \mathrm{m}^{2}$ & 2.20 & $1.12-4.34$ & 0.022 \\
Cigarette smoking & 0.57 & $0.21-1.53$ & 0.264 \\
Alcohol intake & 1.47 & $0.64-3.35$ & 0.362 \\
Comorbidity & & & \\
$\quad$ Hypertension & 0.61 & $0.25-1.49$ & 0.275 \\
$\quad$ Diabetes mellitus & 0.29 & $0.63-1.33$ & 0.111 \\
$\quad$ NP follow-up or NP medication & 2.44 & $1.23-4.85$ & 0.011 \\
Hiatal hernia & 0.31 & $0.31-2.27$ & 0.831 \\
Disease classification & & & \\
$\quad$ ERD & 1 & & \\
$\quad$ NERD & 3.30 & $1.54-7.11$ & 0.002 \\
Total GIS score & 0.97 & $0.93-1.02$ & 0.251 \\
Total ESS score & 1.04 & $0.95-1.14$ & 0.440 \\
Total PSQI score & 1.20 & $1.05-1.35$ & 0.005 \\
Total HADS score & 1.03 & $0.98-1.09$ & 0.267 \\
Total WHOQOL-BREF score & 0.99 & $0.95-1.02$ & 0.451 \\
\hline
\end{tabular}

PPI, proton pump inhibitor; OR, odds ratio; CI, confidence interval; BMI, body mass index; NP, neuropsychiatry; ERD, erosive reflux disease; NERD, non-erosive reflux disease; GIS, gastroesophageal reflux disease impact scale; ESS, Epworth sleepiness scale; PSQI, Pittsburgh sleep quality index; HADS, hospital anxiety and depression scale; WHOQOL-BREF, World Health Organization quality of life scale abbreviated version.

${ }^{a}$ Multivariate logistic regression analysis adjusted for age and gender.

study, it comprehensively examined factors related to PPI response. The overall proportion of poor responders to PPI therapy $(28.5 \%)$ is similar to results reported in another multicenter, multinational, prospective study. ${ }^{8}$ The present study used a multivariate analysis to determine that higher total PSQI score, history of psychotherapy or neuropsychiatric medication, BMI $<23$ $\mathrm{kg} / \mathrm{m}^{2}$, and NERD were significantly associated with poor response of GERD symptoms to PPI therapy. In addition, BMI $<23 \mathrm{~kg} / \mathrm{m}^{2}$ and higher total PSQI score were also significantly related to a non-response to PPI treatment in NERD patients using multivariate analysis.

Previous studies have shown that patients with NERD typically do not respond well to PPI treatment when compared to patients with ERD, and our results were consistent with these previous findings. ${ }^{25,26}$ Among NERD patients, patient's perception of significantly increased reflux was observed not only with acidic reflux but also with weak acidic reflux and gas in the refluxate. ${ }^{27}$ In addition, a previous study found that increased sensitivity to esophageal pain was present in a subset of PPI-resistant NERD
Table 5. Factors Predicting Poor Response to Proton Pump Inhibitor Therapy According to the Subtype of Gastroesophageal Reflux Disease

\begin{tabular}{lcc}
\hline & \multicolumn{2}{c}{ Poor response to PPI } \\
\cline { 2 - 3 } \multicolumn{1}{c}{ Variables } & $\begin{array}{c}\mathrm{ERD}(\mathrm{n}=12)^{\mathrm{a}} \\
\left(\mathrm{OR}[95 \% \mathrm{CI}]^{\mathrm{b}}\right)\end{array}$ & $\begin{array}{l}\text { NERD }(\mathrm{n}=39)^{\mathrm{a}} \\
\left(\mathrm{OR}[95 \% \mathrm{CI}]^{\mathrm{b}}\right)\end{array}$ \\
\hline BMI $<23 \mathrm{~kg} / \mathrm{m}^{2}$ & $1.52(0.29-8.09)$ & $2.74(1.20-6.30)^{\mathrm{c}}$ \\
Cigarette smoking & $0.48(0.08-2.79)$ & $1.13(0.29-4.34)$ \\
Alcohol intake & $0.68(0.14-3.33)$ & $2.28(0.83-6.24)$ \\
Comorbidity & & \\
$\quad$ Hypertension & $1.99(0.51-7.80)$ & $0.27(0.06-1.36)$ \\
Diabetes mellitus & $0.40(0.05-3.49)$ & $0.39(0.04-3.72)$ \\
NP follow-up or NP medication & $1.58(0.37-6.76)$ & $2.01(0.88-4.55)$ \\
Hiatal hernia & $1.35(0.34-5.60)$ & $1.03(0.16-6.50)$ \\
Total GIS score & $0.99(0.87-1.12)$ & $1.01(0.95-1.06)$ \\
Total ESS score & $0.95(0.77-1.18)$ & $1.13(0.98-1.31)$ \\
Total PSQI score & $1.19(0.91-1.55)$ & $1.18(1.02-1.37)^{\mathrm{c}}$ \\
Total HADS score & $0.97(0.84-1.11)$ & $1.04(0.97-1.11)$ \\
Total WHOQOL-BREF score & $0.94(0.86-1.02)$ & $1.00(0.96-1.05)$ \\
\hline
\end{tabular}

PPI, proton pump inhibitor; ERD, erosive reflux disease; NERD, non-erosive reflux disease; $\mathrm{OR}$, odds ratio; $\mathrm{CI}$, confidence interval; $\mathrm{BMI}$, body mass index; $\mathrm{NP}$, neuropsychiatry; GIS, gastroesophageal reflux disease impact scale; ESS, Epworth sleepiness scale; PSQI, Pittsburgh sleep quality index; HADS, hospital anxiety and depression scale; WHOQOL-BREF, World Health Organization quality of life scale abbreviated version.

${ }^{a}$ The numbers indicate PPI non-responders in each group, ${ }^{b}$ Multivariate logistic regression analysis adjusted for age and gender, ${ }^{\mathrm{C}}$ Statistical significance.

patients. ${ }^{28}$ Therefore, reflux perception and increased sensitivity to pain may be associated with different responses to PPI therapy in ERD vs NERD patients.

Our study revealed a significant association between BMI and response to PPI. This is similar to previous studies reporting BMI as a predictive factor of PPI response in GERD patients. Peura et $\mathrm{al}^{29}$ showed that baseline heartburn severity increased with increasing BMI in both ERD and NERD patients, while Fletcher et $\mathrm{al}^{30}$ revealed a positive association between higher BMI and symptom improvement after lansoprazole therapy in patients with a wide range of upper gastrointestinal symptoms and normal gastroscopy. These findings suggest that PPIs could be more effective in patients with a higher BMI and severe GERD symptoms. In other words, lower BMI may be a risk factor for PPI non-responsiveness.

There are many clinical studies that have evaluated the relationship between GERD and sleep disturbances. ${ }^{31,32}$ Schey et $\mathrm{al}^{33}$ performed an experimental study and demonstrated the effect of sleep deprivation on perception of intraesophageal acid infusion. Shorter sleep duration ( $\leq 3$ hours) decreased the latency and increased the intensity of GERD symptoms induced by intra- 
esophageal acid infusion compared with longer sleep duration ( $\geq 7$ hours). The authors suggested that sleep deprivation could cause esophageal hyperalgesia. ${ }^{31,33}$ Overall sleep quality, including sleep duration, may be associated with more severe GERD symptoms and could influence response to PPI therapy in GERD patients. ${ }^{33}$ A previous study by the authors of the present paper demonstrated that poor sleep quality is more strongly associated with NERD than with ERD. ${ }^{18}$ Therefore, NERD, a risk factor of poor response to PPI treatment in GERD patients, could also be related to sleep disturbances.

In a population-based study, anxiety and depression were shown to increase the risk of reflux. ${ }^{34}$ In the present study, the frequency of a history of psychotherapy or neuropsychiatric medication was significantly higher in the non-responder group. Nojkov et $\mathrm{al}^{35}$ demonstrated that patients who responded poorly to PPI therapy were more likely to experience psychiatric distress. Psychological stress can aggravate sensitivity to esophageal pain by increasing the perception of esophageal stimuli. ${ }^{36}$ In addition, recent study demonstrated that acute stress induced dilated intercellular spaces in the esophageal mucosa of rats. ${ }^{37}$ Therefore, it has been suggested that psychosocial comorbidity, which is probably associated with a history of psychotherapy or neuropsychiatric medication, could cause esophageal hypersensitivity and poor responses to PPI therapy in patients with GERD symptoms.

This study has several limitations. First, the sample size is small, primarily because there was not enough time to enroll all patients with GERD symptoms in the study. In addition, many of the patients with GERD symptoms initially refused to either answer the questionnaire or undergo esophageal manometry or 24-hour esophageal $\mathrm{pH}$ testing. Thus we could not calculate the number of candidates for enrollment in this study. However, we performed the specific and detailed examinations by experts in each fields, such as endoscopist, physician assistant in the area of motility, and well-trained interviewer. In addition, the current study was approached from various and extensive ways for assessment of the factors response to PPI treatment including epidemiologic factors, sleep, psychological co-morbidity, QOL and so forth.

In conclusion, a BMI $<23 \mathrm{~kg} / \mathrm{m}^{2}$, sleep dysfunction, a history of psychotherapy or neuropsychiatric medication, and NERD appear to be predictive factors of poor response to PPI in Korean patients with GERD.

\section{References}

1. Vakil N, van Zanten SV, Kahrilas P, Dent J, Jones R; Global Consensus Group. The Montreal definition and classification of gastroesophageal reflux disease: a global evidence-based consensus. Am J Gastroenterol 2006;101:1900-1920.

2. Lee ES, Kim N, Lee SH, et al. Comparison of risk factors and clinical responses to proton pump inhibitors in patients with erosive oesophagitis and non-erosive reflux disease. Aliment Pharmacol Ther 2009;30:154-164.

3. Katz PO, Gerson LB, Vela MF. Guidelines for the diagnosis and management of gastroesophageal reflux disease. Am J Gastroenterol 2013;108:308-328.

4. Shi S, Klotz U. Proton pump inhibitors: an update of their clinical use and pharmacokinetics. Eur J Clin Pharmacol 2008;64:935-951.

5. El-Serag H, Becher A, Jones R. Systematic review: persistent reflux symptoms on proton pump inhibitor therapy in primary care and community studies. Aliment Pharmacol Ther 2010;32:720-737.

6. Viazis N, Karamanolis GP, Anastasiou J, et al. Refractory GERD: increased body mass index is associated with persisting acid exposure but not hypersensitive esophagus or functional heartburn. Eur J Gastroenterol Hepatol 2013;25:1450-1455.

7. Hershcovici T, Fass R. An algorithm for diagnosis and treatment of refractory GERD. Best Prac Res Clin Gastroenterol 2010;24:923936.

8. Heading RC, Mönnikes H, Tholen A, Schmitt H. Prediction of response to PPI therapy and factors influencing treatment outcome in patients with GORD: a prospective pragmatic trial using pantoprazole. BMC Gastroenterol 2011;11:52.

9. Wang AJ, Wang $\mathrm{H}, \mathrm{Xu} \mathrm{L}$, et al. Predictors of clinical response of acid suppression in Chinese patients with gastroesophageal reflux disease. Dig Liver Dis 2013;45:296-300.

10. Jo HJ, Lee HS, Kim N, et al. Predictable marker for regression of Barrett's esophagus by proton pump inhibitor treatment in Korea. J Neurogastroenterol Motil 2013;19:210-218.

11. Seo GS, Jeon BJ, Chung JS, et al. The prevalence of erosive esophagitis is not significantly increased in a healthy Korean population could it be explained?: a multi-center prospective study. J Neurogastroenterol Motil 2013;19:70-77.

12. Lee JY, Kim N, Kim SE, et al. Clinical characteristics and treatment outcomes of 3 subtypes of achalasia according to the chicago classification in a tertiary institute in Korea. J Neurogastroenterol Motil 2013;19:485-494.

13. Bredenoord AJ, Fox M, Kahrilas PJ, et al. Chicago classification criteria of esophageal motility disorders defined in high resolution esophageal pressure topography. Neurogastroenterol Motil 2012;24 (suppl 1):57-65.

14. Jones R, Coyne K, Wiklund I. The gastro-oesophageal reflux disease impact scale: a patient management tool for primary care. Aliment Pharmacol Ther 2007;25:1451-1459.

15. Buysse DJ, Reynolds CF 3rd, Monk TH, Berman SR, Kupfer DJ. The Pittsburgh Sleep Quality Index: a new instrument for psychiatric practice and research. Psychiatry Res 1989;28:193-213.

16. Jo SY, Kim N, Lim JH, et al. Comparison of gastroesophageal reflux 
disease symptoms and proton pump inhibitor response using gastroesophageal reflux disease impact scale questionnaire. J Neurogastroenterol Motil 2013;19:61-69.

17. Johns MW. A new method for measuring daytime sleepiness: the Epworth sleepiness scale. Sleep 1991;14:540-545.

18. Kim JY, Kim N, Seo PJ, et al. Association of sleep dysfunction and emotional status with gastroesophageal reflux disease in Korea. J Neurogastroenterol Motil 2013;19:344-354.

19. Buysse DJ, Hall ML, Strollo PJ, et al. Relationships between the Pittsburgh Sleep Quality Index (PSQI), Epworth Sleepiness Scale (ESS), and clinical/polysomnographic measures in a community sample. J Clin Sleep Med 2008;4:563-571.

20. Bjelland I, Dahl AA, Haug TT, Neckelmann D. The validity of the Hospital Anxiety and Depression Scale. An updated literature review. J Psychosom Res 2002;52:69-77.

21. Development of the World Health Organization WHOQOLBREF quality of life assessment. The WHOQOL Group. Psychol Med 1998;28:551-558.

22. Sohn SI, Kim do H, Lee MY, Cho YW. The reliability and validity of the Korean version of the Pittsburgh Sleep Quality Index. Sleep Breath 2012;16:803-812.

23. Cho YW, Lee JH, Son HK, Lee SH, Shin C, Johns MW. The reliability and validity of the Korean version of the Epworth sleepiness scale. Sleep Breath 2011;15:377-384.

24. Min SK, Kim KI, Lee CI, Jung YC, Suh SY, Kim DK. Development of the Korean versions of WHO quality of life scale and WHOQOL-BREF. Qual Life Res 2002;11:593-600.

25. Dean BB, Gano AD Jr, Knight K, Ofman JJ, Fass R. Effectiveness of proton pump inhibitors in nonerosive reflux disease. Clin Gastroenterol Hepatol 2004;2:656-664.

26. Scarpignato C. Poor effectiveness of proton pump inhibitors in non-erosive reflux disease: the truth in the end! Neurogastroenterol Motil 2012;24:697-704.

27. Emerenziani S, Sifrim D, Habib FI, et al. Presence of gas in the re- fluxate enhances reflux perception in non-erosive patients with physiological acid exposure of the oesophagus. Gut 2008;57:443-447.

28. Hobson AR, Furlong PL, Aziz Q. Oesophageal afferent pathway sensitivity in non-erosive reflux disease. Neurogastroenterol Motil 2008;20:877-883.

29. Peura DA, Pilmer B, Hunt B, Mody R, Perez MC. The effects of increasing body mass index on heartburn severity, frequency and response to treatment with dexlansoprazole or lansoprazole. Aliment Pharmacol Ther 2013;37:810-818.

30. Fletcher J, Derakhshan MH, Jones GR, Wirz AA, McColl KE. $\mathrm{BMI}$ is superior to symptoms in predicting response to proton pump inhibitor: randomised trial in patients with upper gastrointestinal symptoms and normal endoscopy. Gut 2011;60:442-448.

31. Fujiwara Y, Arakawa T, Fass R. Gastroesophageal reflux disease and sleep disturbances. J Gastroenterol 2012;47:760-769.

32. Ju G, Yoon IY, Lee SD, Kim N. Relationships between sleep disturbances and gastroesophageal reflux disease in Asian sleep clinic referrals. J Psychosom Res 2013;75:551-555.

33. Schey R, Dickman R, Parthasarathy S, et al. Sleep deprivation is hyperalgesic in patients with gastroesophageal reflux disease. Gastroenterology 2007;133:1787-1795.

34. Sifrim D, Zerbib F. Diagnosis and management of patients with reflux symptoms refractory to proton pump inhibitors. Gut 2012;61: 1340-1354.

35. Nojkov B, Rubenstein JH, Adlis SA, et al. The influence of co-morbid IBS and psychological distress on outcomes and quality of life following PPI therapy in patients with gastro-oesophageal reflux disease. Aliment Pharmacol Ther 2008;27:473-482.

36. Fass R, Naliboff BD, Fass SS, et al. The effect of auditory stress on perception of intraesophageal acid in patients with gastroesophageal reflux disease. Gastroenterology 2008;134:696-705.

37. Farré R, De Vos R, Geboes K, et al. Critical role of stress in increased oesophageal mucosa permeability and dilated intercellular spaces. Gut 2007;56:1191-1197. 